\title{
Monoamine Oxidase A Activity and Norepinephrine Level in Hippocampus Determine Hyperwheel Running in SPORTS Rats
}

\author{
Masaki Morishima', Nagakatsu Harada*,', Sayuri Hara', Atsuko Sano², Hiromasa Seno ${ }^{2}$, Akira Takahashi', \\ Yusuke Morita $^{2}$ and Yutaka Nakaya' \\ 'Department of Nutrition and Metabolism, Institute of Health Biosciences, The University of Tokushima Graduate School, Kuramoto-cho, \\ Tokushima City, Japan; 'Department of Integrative Physiology, Institute of Health Biosciences, The University of Tokushima Graduate School, \\ Kuramoto-cho, Tokushima City, Japan
}

\begin{abstract}
An understanding of neurological mechanisms for wheel running by rodents, especially with high exercise activity, would be applicable to a strategy for promotion of exercise motivation in humans. One of several brain regions that are candidates for the regulation of physical exercise is the hippocampus. Here we examined the running activity of Spontaneously-Running-Tokushima-Shikoku (SPORTS) rat, a new animal model for high levels of wheel-running activity, and its relation with the hippocampal norepinephrine (NE) system including the levels of NE, adrenergic receptors, and degradation enzymes for monoamines. In the hippocampus of SPORTS rats, the level of NE in extracellular fluid was augmented, whereas the level in the homogenate of the whole tissue was decreased even for sedentary conditions. Elevated extracellular NE caused downregulation of $\alpha_{2}$-adrenergic receptors in the hippocampus of SPORTS rats. Local administration of $\alpha_{2}$-adrenergic receptor antagonist yohimbine, but not of $\alpha_{2}$-agonist clonidine, into the hippocampus suppressed high running activity in SPORTS rats. The protein expression and the activity levels of monoamine oxidase A (MAOA), a critical enzyme for the degradation of NE, were decreased in the hippocampus of SPORTS rats to increase extracellular NE level. Thus, inhibition of oxidase activity in normal Wistar rats markedly increased wheel-running activity. These results indicate that decreased MAOA activity, elevation of extracellular NE, and $\alpha_{2}$-adrenergic receptors in the hippocampus determine the neural basis of the psychological regulation of exercise behavior in SPORTS rats.

Neuropsychopharmacology (2006) 3 I, 2627-2638. doi:10.1038/sj.npp. I 30 I028; published online 18 January 2006
\end{abstract}

Keywords: exercise behavior; hyper-running; monoamine oxidase A; norepinephrine; hippocampus; $\alpha_{2}$-adrenergic receptor

\section{INTRODUCTION}

Increased physical activity is now widely recommended for the maintenance of health as well as for the treatment of various metabolic disorders such as diabetes, obesity, and hypertension (Sheard, 2003; Weinsier et al, 1998; Cortez et al, 1991; Fiebig et al, 2002; Lapier et al, 2001). Many people in the developed countries choose not to be active physically, possibly because of a reduced motivation to participate in exercise activities (Biddle and Fox, 1998).

\footnotetext{
*Correspondence: Dr N Harada, Department of Nutrition and Metabolism, Institute of Health Biosciences, The University of Tokushima Graduate School, 3-I8-15, Kuramoto-cho, Tokushima City, Tokushima 770-8503, Japan, Tel: +81 88633 7090, Fax: + 8188633 7| |3, E-mail: harada@nutr.med.tokushima-u.ac.jp

Received 25 August 2005; revised 6 December 2005; accepted 8 December 2005

Online publication: 21 December 2005 at http://www.acnp.org/ citations/Npp 122 1 05050533/default.pdf
}

Formal or clinical education for facilitating exercise training sometimes helps to enhance a person's motivational level (Phillips et al, 2004). Pharmacological or nutritional methods, which target and activate the molecular machinery in the brain directly, are expected to be available in the future for the treatment of reduced exercise motivation. At present, however, the psychology and the molecular biology of exercise initiation and adherence are under-researched (Biddle and Fox, 1998; Sherwin, 1998).

Wheel running by rodents is thought to reflect voluntary exercise training in humans (Eikelboom, 1999). Observations for overweight, physically inactive humans and of early dropouts from formal exercise programs (Dishman, 1981) were consistent with the results of animal experiments where obese and diabetic animals showed low wheelrunning activity (Harada et al, 2002; Marshall et al, 1976). Thus, an understanding of brain mechanisms for wheel running by rodents, especially with high exercise activity, would contribute to promotion of exercise motivation in humans. There are a few animal models of high wheel- 
running activity (Swallow et al, 1998; Wilckens et al, 1992) but the mechanism for this behavior is still unknown.

We have established a line of rats that has high wheelrunning activity and was named SPORTS (SpontaneouslyRunning-Tokushima-Shikoku). The line was discovered in an outbred strain of Wistar rats (Morishima-Yamato et al, 2005). Male SPORTS rats run voluntarily in the running wheel almost six times longer than control Wistar rats (Morishima-Yamato et al, 2005). The hyper-running of SPORTS rats brought about a greater decrease in body fat and blood glucose levels than in low-running controls (Morishima-Yamato et al, 2005). Thus, the SPORTS rats are a useful model for determining the psychological mechanisms of increased exercise behavior.

One of several brain regions that are candidates for the regulation of physical exercise is the hippocampus (Tong et al, 2001; Bronikowski et al, 2004). The hippocampus has a central role in regulating positive affect, learning, memory functions, and emotion (Cahill et al, 1994; LeDoux, 1994). The hippocampus is sensitive to stress and to physical exercise, both of which activate norepinephrine (NE) terminals deriving from the locus ceruleus (Bremner et al, 1996; Xu et al, 2000; Carter, 1997). Following exercise stimulation, a variety of changes in gene expression and $\mathrm{NE}$ metabolism occurred in the hippocampus (Bronikowski et al, 2004; Dunn et al, 1996; Rhodes et al, 2003). Whether hippocampal NE induces voluntary wheel running has not yet been clarified, although genetically or pharmacologically enhanced $\mathrm{NE}$ level in brain regions that include the hippocampus increases field locomotor activity in experimental animals (Xu et al, 2000; Cryan et al, 2004; Shishikina et al, 2004; Lahdesmaki et al, 2003; Cases et al, 1995). Given the fact that obese and diabetic animals with low physical activity have less $\mathrm{NE}$ in the hippocampus than normal controls (Gallego et al, 2003; Yamato et al, 2004; Lackovic et al, 1990), we hypothesized that hippocampal $\mathrm{NE}$ is involved in the initiation of voluntary exercise.

We investigated the NE system, including its levels, receptors, and degradation enzymes, in the hippocampus of SPORTS rats. The results obtained from this study show that extracellular NE neurotransmission in the hippocampus of SPORTS rats is activated even in sedentary conditions without wheel running. These findings indicate that hippocampal NE is a neural basis for and a molecular target of the psychological regulation of exercise behavior.

\section{MATERIALS AND METHODS}

\section{Animals}

Male SPORTS rats that had been established in our laboratory (Morishima-Yamato et al, 2005) were used for this study. Another line of Wistar rats in which sequential mating had been conducted without selection for running activity was used as age-matched controls (MorishimaYamato et al, 2005). The rats at 16 weeks of age were mainly used for this study since the SPORTS rats at this age point showed almost six times higher running activity than control rats (Morishima-Yamato et al, 2005). In some experiments, the rats aged 4 weeks were also used since at this age point the hyper-running phenotype does not yet appear in the SPORTS strain (Morishima-Yamato et al,
2005). All the rats were housed singly at a constant room temperature of $23 \pm 1{ }^{\circ} \mathrm{C}$ with a 12-h light/dark cycle, and were fed a standard nonpurified diet (Oriental Yeast, Tokyo, Japan) with food and water available ad libitum. Different sets of animals were used for the different analyses. This study conformed to the guidlines for the care and use of Laboratory animals of The University of Tokushima Graduate School Institute of Health Bioscience. All efforts were made to minimize animal suffering and to reduce the number of animals used in the experiments.

\section{In Vivo Brain Microdialysis}

Male SPORTS and control rats aged 3-4 weeks were housed singly in cages without an exercise wheel until 16 weeks of age. Rats were anesthetized by intraperitoneal injection of sodium pentobarbital $(50 \mathrm{mg} / \mathrm{kg})$, and a stainless-steel guide cannula was inserted into the left striatum $(\mathrm{AP}=+0.2$, $L=3.5, \quad V=3.0$, taken from bregma) or left ventral hippocampus $(\mathrm{AP}=-5.6, L=4.4, V=3.5$, taken from bregma) according to the atlas of Paxinos and Watson (1986). The guide cannula was fixed in the skull by two round-tip miniature screws and dental acrylic cement. A stainless-steel dummy cannula was inserted into the guide and kept there until the start of the experiment. After surgery, rats were allowed to recover in specific cages $\left(30 \times 30 \times 35 \mathrm{~cm}^{3}\right)$ for at least 5 days (Sei et al, 2003). Then, the dummy cannula was removed and a microdialysis probe cannula with a $4-\mathrm{mm}$ long semipermeable membrane (10000 mol Molecular cutoff, Eicom, Kyoto, Japan) was inserted into the striatum or hippocampus through the guide cannula and fixed. Microdialysis experiments were carried out the next day. The probe cannula was perfused with Ringer solution $(147 \mathrm{mM} \mathrm{NaCl}, 4 \mathrm{mM} \mathrm{KCl}$, $2.25 \mathrm{mM} \mathrm{CaCl}_{2}$ ) at a constant rate of $1 \mu \mathrm{l} / \mathrm{min}$. After a 3-h equilibration period, perfusate samples were collected each $60 \mathrm{~min}$ from 1400 to 2000 (lights off at 2000). Perfusate samples were mixed with $0.02 \mathrm{M}$ acetic acid solution containing $10 \mu \mathrm{M}$ EDTA and were frozen rapidly and stored at $-80^{\circ} \mathrm{C}$ until high-pressure liquid chromatography (HPLC) analysis.

\section{Preparation of Tissue Homogenates for HPLC Analysis}

After the microdialysis experiments, the rats were anesthetized with sodium pentobarbital $(50 \mathrm{mg} / \mathrm{kg})$ and killed by decapitation. The striatum and hippocampus were isolated rapidly at $4{ }^{\circ} \mathrm{C}$ and were frozen immediately in liquid nitrogen and stored at $-80^{\circ} \mathrm{C}$. Each sample was homogenized in five volumes of $0.2 \mathrm{M}$ perchloric acid with a glass microhomogenizer (A-1000, TOP, Tokyo, Japan). The homogenate was centrifuged at $20000 \mathrm{~g}$ for $15 \mathrm{~min}$ at $4^{\circ} \mathrm{C}$. The supernatants were acidified to $\mathrm{pH} 3.0$ by the addition of $1 \mathrm{M}$ sodium acetate. Samples were then filtered through a Minisart RC 4 filter (Sartorius AG, Goettingen, Germany) for HPLC analysis.

\section{Measurement of Catecholamine Levels in the Perfusate and Tissue Homogenates}

Dopamine (DA), L-3,4-dihydroxyphenylacetic acid (DO$\mathrm{PAC}$ ), and $\mathrm{NE}$ in the perfusate or tissue homogenate were 
separated by a HPLC system (EICOMPAK SC-5ODS column, $150 \times 2.1 \mathrm{~mm}^{2}$, Eicom) and detected by the Model ECD-amperometric detector (Eicom) equipped with a working electrode and an $\mathrm{Ag} / \mathrm{AgCl}$ reference electrode. Mobile phase (containing $17 \%(\mathrm{v} / \mathrm{v})$ methanol, $0.01 \mathrm{mM}$ EDTA, $0.1 \mathrm{M}$ sodium acetic/citric acid, and $1.4 \mathrm{mM}$ octane sulphonic acid, $\mathrm{pH} 3.9$ ) was pumped at a flow rate of $0.25 \mu \mathrm{l} /$ min. DA, DOPAC and NE were eluted by this program at representative retention times of $7.6,6.8$, and $4 \mathrm{~min}$, respectively. Macintosh-based PowerChrom v2.1 software (Eicom) was used for data analysis.

\section{Radioligand-Binding Assay}

The hippocampus was isolated from rat brain and frozen at $-80^{\circ} \mathrm{C}$ for at least 1 week before use. The tissue sample was homogenized briefly in $2 \mathrm{ml}$ cold homogenization buffer (20 mM HEPES, $100 \mathrm{mM} \mathrm{NaCl}, 10 \mathrm{mM} \mathrm{MgCl} 2,1 \mathrm{mM}$ EDTA, $1 \mathrm{mM}$ 1,4-Dithio-DL-threitol, $\mathrm{pH}$ 7.4) followed by centrifugation at $20000 \mathrm{~g}$ for $15 \mathrm{~min}$ at $4^{\circ} \mathrm{C}$. Precipitated crude membrane fraction was resuspended in the assay buffer (20 mM HEPES, $150 \mathrm{mM} \mathrm{NaCl}, 10 \mathrm{mM} \mathrm{MgCl}_{2}, \mathrm{pH} \mathrm{7.4)}$ and the protein concentration was measured with a bicinchoninic acid protein assay kit (Pierce, Rockford, IL). In all, $30 \mu \mathrm{g}$ of membrane protein was then incubated in the presence of $625 \mathrm{nM}^{3} \mathrm{H}-\mathrm{NE}(7.94 \mathrm{Ci} / \mathrm{mmole}, \mathrm{ARC}$ Inc.) and $625 \mu \mathrm{M} \mathrm{NE}$ or $625 \mu \mathrm{M}$ of each competitor prazosin $\left(\alpha_{1 / 2^{-}}\right.$ adrenergic receptor (AR) antagonist), yohimbine $\left(\alpha_{2}\right.$-AR antagonist), propranolol ( $\beta$-AR antagonist), and phenylephrine $\left(\alpha_{1}\right.$-AR agonist) $)$ at $25^{\circ} \mathrm{C}$. After $60 \mathrm{~min}$, the mixture was applied onto a GF/C filter (Whatmann, Maidstone, UK), the filter was washed three times with ice-cold $10 \mathrm{mM}$ Tris$\mathrm{HCl}$ buffer (pH7.4), and the filter was counted with a liquid scintillation counter. The radioactivity (counts per minute $(\mathrm{CPM})$ ) in the presence of nonlabeled NE was regarded as the amount of nonspecific binding of ${ }^{3} \mathrm{H}-\mathrm{NE}$ and was subtracted from each test sample count. Specific binding of ${ }^{3} \mathrm{H}-\mathrm{NE}$ to each AR was calculated by subtracting CPM in the presence of competitor from that in the absence of competitor.

\section{Western Blot Analysis}

The hippocampus, cerebral cortex, and liver were isolated from rats rapidly at $4{ }^{\circ} \mathrm{C}$. Tissue samples were homogenized in ice-cold Tris- $\mathrm{HCl}$ buffer at a $\mathrm{pH}$ of 8.0 in the presence of $1 \%$ Nonidet-P40, $10 \%$ glycerol, and $1 \mathrm{mM}$ phenylmethyl sulfonyl fluoride. In all, $50 \mu \mathrm{g}$ of protein was denatured by boiling for $5 \mathrm{~min}$ in the loading buffer (4\% sodium dodecyl sulfate (SDS), $250 \mathrm{mM}$ Tris- $\mathrm{HCl}, \mathrm{pH} 6.8,1 \% \quad \beta$-mercaptoethanol, $1 \%$ bromophenol blue, and $20 \%$ glycerol). The proteins were subjected to SDS-polyacrylamide gel electrophoresis and transferred onto a nitrocellulose membrane (PROTRAN, S\&S, Bioscience, Germany). The membrane was blocked using 5\% skim milk in Tris-buffered saline containing $0.05 \%$ Tween 20 for $1 \mathrm{~h}$ and incubated with a rabbit antimonoamine oxidase (MAO) A antibody (1:200, Santa Cruz Biotechnology Inc., CA, USA), rabbit antimonoamine oxidase B (MAOB) antibody (1:100, Santa Cruz), rabbit anticatechol-O-methyltransferase (COMT) antibody (1:1000, BD Transduction Laboratories, Lexington, KY), rabbit anti- $\alpha_{2 A}-A R$ antibody (1:500, Sigma, St. Louis, MO), rabbit anti- $\alpha_{1}-\mathrm{AR}$ antibody (1:500, Sigma) or rabbit antiguanine nucleotide-binding protein (G $\alpha \mathrm{i})$ antibody (1:500, BD Transduction Laboratories). The blot was visualized with anti-rabbit IgG horseradish peroxidase conjugate secondary antibody (1:2000, Biosource International, Camarillo, CA) and an ECL detection system (Amersham Pharmacia Biotech, Aylesbury, UK).

\section{Northern Blot Analysis}

Total RNA was extracted from rat hippocampus with TRIzol reagent (Invitrogen, Carlsbad, CA). Of total RNA, $25 \mu \mathrm{g}$ was subjected to electrophoresis on a $1 \%$ denaturing agarose gel and transferred to a Gene Screen membrane (NEN Life Science Products, Boston, MA). Double-stranded cDNA encoding rat MAOA (GenBank accession number; XM343764), MAOB (NM013198), COMT (NM012531), and glyceraldehyde 3-phosphate dehydrogenase (G3PDH, $\mathrm{X} 02231$ ) were generated by the reverse transcriptionpolymerase chain reaction (RT-PCR) of rat hippocampus RNA, and cloned into $\mathrm{pCR}^{\mathrm{R}}$-Blunt II-TOPO vector using the TOPO cloning system (Invitrogen). The nucleotide sequencing was carried out for each insert with an ABI 377 DNA sequencer (Applied Biosystems, Foster City, CA) and a BigDye dye-terminator sequencing system (Applied Biosystems) following the manufacturer's protocol. EcoRIdigested fragments were then labeled with $\left(\alpha-{ }^{32} \mathrm{P}\right)$ dCTP by a Megaprime labeling system (Amersham Pharmacia Biotech) and used as the probes. Membrane protein was hybridized with the probe at $42^{\circ} \mathrm{C}$ overnight, washed, and exposed to Kodak BIOMAX ${ }^{\mathrm{TM}} \mathrm{MS}$ film at $-80^{\circ} \mathrm{C}$.

\section{Sequencing of Open Reading Frame for MAOA mRNA}

Double-stranded cDNA encoding rat MAOA with full open reading frame was generated by RT-PCR of rat hippocampus RNA using specific primers upstream of the translation initiation codon ( $5^{\prime}$-CCTTAAAGCGGAGCGCTGTT-3') and downstream of the translational stop codon $\left(5^{\prime}\right.$-ACATGC GATGATCGTGCAGG- $3^{\prime}$ ). The subcloning of PCR product into the vector and the subsequent nucleotide sequencing were conducted as described above.

\section{Measurement of MAO Activity}

Activities of MAOA and MAOB in tissue homogenates were measured with the Amplex Red Monoamine Oxidase Assay kit (Molecular Probes, Oregon, USA (Mingjie and Nataliya, 1997)) according to the manufacture's protocol. Enzyme activity was expressed as nmol substrate catalyzed $/ \mathrm{min} / \mathrm{mg}$ protein.

\section{Treatment of Rat Hippocampus with Agonist or Antagonist for $\alpha_{2}$-AR}

Male SPORTS and control Wistar rats 3-4 weeks old were housed singly in cages with an exercise wheel $(1.15 \mathrm{~m} /$ cycle, Nishin, Tokushima, Japan) until 15 weeks of age. At 15 weeks of age, rats were anesthetized and a microdialysis probe cannula was bilaterally set in hippocampus as described above. The hippocampus was perfused for $45 \mathrm{~min}$ with Ringer solution containing either clonidine 
$\left(\alpha_{2}\right.$-AR agonist, $\left.100 \mu \mathrm{M}\right)$ or yohimbine $(20 \mu \mathrm{M})$ at a rate of $1 \mu \mathrm{l} / \mathrm{min}$ under conditions where the rats were freely moving without anesthesia. The dosages of these drugs were based on results of previous studies (Finberg et al, 1993). Both drugs were freshly prepared prior to use. Each vehicle group was perfused only with the Ringer solution. Drug perfusion was finished at 2200 and the revolution number of the running wheel for each rat was monitored thereafter for $2 \mathrm{~h}$.

\section{Intraperitoneal Treatment of Rats with MAOA Inhibitor}

Male Wistar rats at 25 weeks of age were purchased from Charles River (Quebec, Canada) and were housed singly in cages with an exercise wheel. Rats were divided randomly into a saline-treated group $(n=3)$ and a clorgyline (MAOA inhibitor)-treated group $(n=3)$. Saline $(0.9 \%)$ vehicle or clorgyline ( $1 \mathrm{mg} / \mathrm{kg} \mathrm{BW/day)} \mathrm{was} \mathrm{injected} \mathrm{intraperitoneally}$ for 4 weeks (Finberg et al, 1994). After injection, the numbers of revolutions of the running wheel for both groups were monitored daily. At $24 \mathrm{~h}$ after the last injection, rats were killed by decapitation under anesthesia. The hippocampus and the liver were isolated immediately and processed for measurement of MAO enzyme activity (see above).

\section{Treatment of Rat Hippocampus with MAOA Inhibitor}

We further studied the local effect of MAOA inhibitor on the hippocampus in male Wistar rats at 25 weeks of age. Rats were anesthetized and a microdialysis probe cannula was bilaterally set in hippocampus as described above. The hippocampus was perfused for $60 \mathrm{~min}$ with Ringer solution (vehicle) or solution containing clorgyline $(1 \mu \mathrm{M})$ at a rate of $1 \mu \mathrm{l} / \mathrm{min}$ under conditions where the rats were freely moving without anesthesia. Drug perfusion was finished at 2200 and the revolution number of the running wheel for each rat was monitored thereafter for $12 \mathrm{~h}$.

\section{Treatment of Rat Hippocampus with Cycloheximide}

The procedure was essentially as described by Hasegawa et al (1995). The hippocampus was isolated and cut into two pieces. The weight of each piece was measured immediately and each piece was incubated for $80 \mathrm{~min}$ at $37^{\circ} \mathrm{C}$ in a Dulbecco's Modified Eagle's Medium under 5\% $\mathrm{CO}_{2} / 95 \%$ $\mathrm{O}_{2}$. Hippocampal pieces were then incubated in the presence of $1 \mu \mathrm{g} / \mathrm{ml}$ cycloheximide in the same buffer for the indicated times. At each time point, a hippocampal piece was washed three times with ice-cold phosphatebuffered saline, homogenized, and Western blotted using rabbit anti-MAOA antibody.

\section{Forced Swim Test}

The procedure was essentially as described by $\mathrm{Xu}$ et al (2000). Briefly, rats were placed into a cylindrical container (59 cm high, $25 \mathrm{~cm}$ diameter) filled with $25^{\circ} \mathrm{C}$ water to a depth of $36 \mathrm{~cm}$. Behavior was recorded on videotape for $15 \mathrm{~min}$ and scored by two independent observers as to the cumulative amount of time (immobility) that the animals spent floating or engaged in minimal activity.

\section{Drugs}

Prazosin, yohimbine, propranolol, clonidine hydrochloride, phenylephrine hydrochloride, and clorgyline hydrochloride were purchased from Sigma. Cycloheximide was purchased from Wako (Osaka, Japan).

\section{Statistical Analysis}

Data are expressed as the means \pm SD. Data were analyzed by ANOVA plus Bonferroni multiple comparison tests. A $p$-value $<0.05$ was accepted as statistically significant.

\section{RESULTS}

\section{SPORTS Rats Show Hyper-Running in Exercise Wheel}

The wheel-running activities of the SPORTS and control Wistar rats were recorded every week. Throughout their growth period in this study, SPORTS rats ran much more than control rats (Figure 1a). Peak revolution number for SPORTS rats was six to 10 times that for control rats (SPORTS, $11843 \pm 2306$; control, $1762 \pm 751 \mathrm{~m} /$ day, $p<0.01)$. As shown in Figure 1b, SPORTS rats concentrated their hyper-running in the dark environment (from 2000 to 0800 in our housing condition). SPORTS rats started running after dark and kept a constant running pace throughout the dark period (Figure 1c).

\section{SPORTS Rats have High Activity in the Forced Swim Test}

Active struggling responses in the Porsolt forced swim test suggest that the animal has high monoaminergic activity in the brain (Xu et al, 2000). As shown in Figure 1d, the time of immobility in water was significantly lower for SPORTS rats than for control rats during the 15-min observation, suggesting a possible enhancement of neurotransmission in the brains of SPORTS rats.

\section{Extracellular NE Levels were Increased in the Hippocampus of SPORTS Rats}

To examine whether the monoaminergic systems are activated in the brains of SPORTS rats, we measured the concentrations of $\mathrm{NE}$ and $\mathrm{DA}$ in brain regions having rich amounts of these monoamines. It is expected that $\mathrm{NE}>\mathrm{DA}$ in the hippocampus and DA $>\mathrm{NE}$ in the striatum (Xu et al, 2000, Cryan et al, 2004). The brain microdialysis study revealed that extracellular NE level in the hippocampus of SPORTS rats was significantly greater than that of control rats all day (Figure 2a). In contrast to NE, the amount of extracellular DA in the striatum was the same in the two groups for any time period (Figure $2 \mathrm{~b}$ ). We failed to detect measurable NE or DA in the striatum or hippocampus, respectively, using our measuring system. The NE contents in the homogenates of whole hippocampus and cerebellum were lower in SPORTS rats than in controls, indicating that $\mathrm{NE}$ was highly concentrated in the extracellular space but not in the intracellular space of the hippocampus in SPORTS rats (Figure 2c). The levels of DA and the DA 

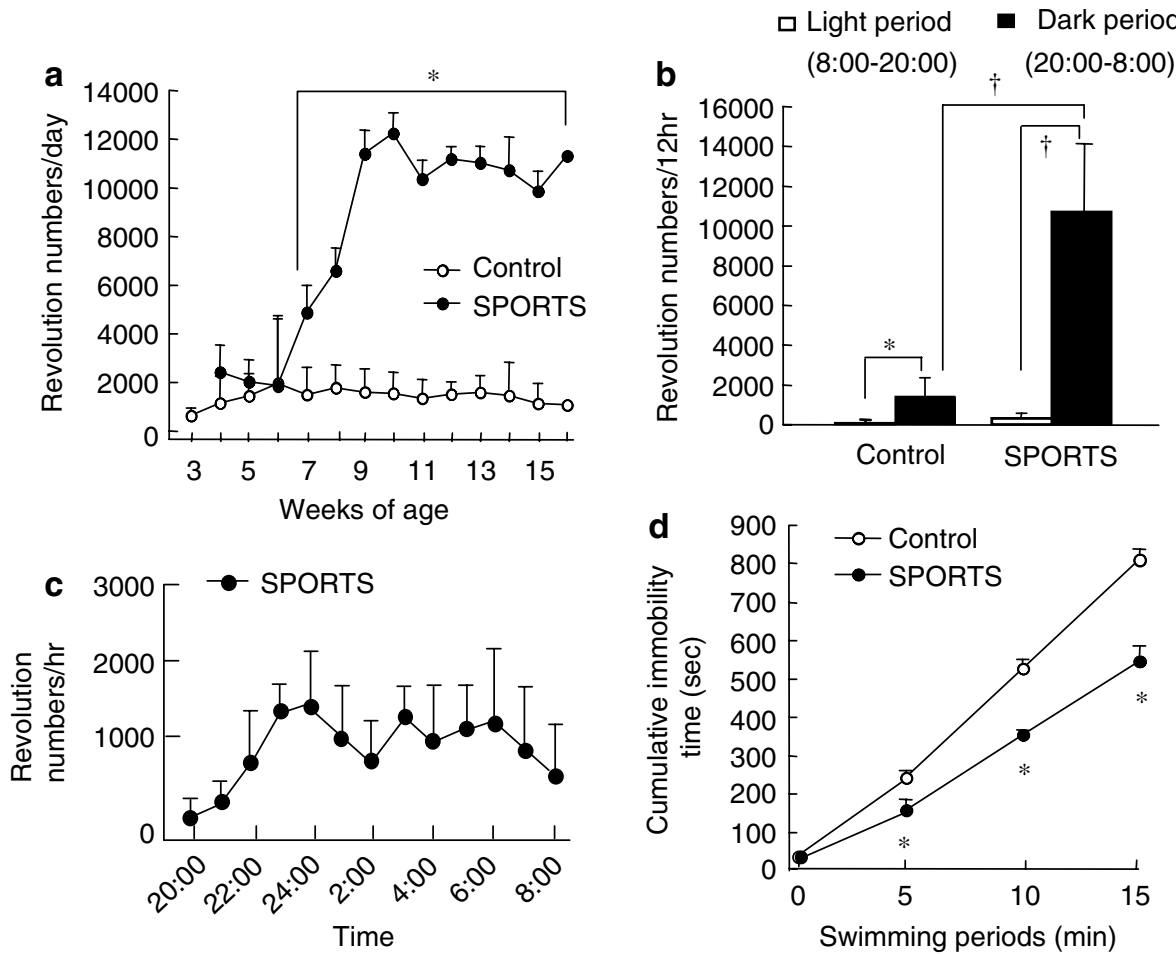

Figure I SPORTS rats show hyper-running in exercise wheel and have high activity in the forced swim test. (a) Mean revolution numbers of the running wheel for SPORTS (closed circles) and control (open circles) rats throughout their growth. (b) The running activities for SPORTS and control rats during environmental light (0800-2000 h) and dark (2000-0800 h) periods. (c) Hourly running activity for SPORTS rats during the environmental dark period. (d) Immobility times during a 15 -min observation period after immersion of rats in water. Data are expressed as means \pm SD for seven (a-c) and four (d) rats in each group. Rats at 16 weeks of age were used in the experiments of $b-d .{ }^{*} p<0.05$ compared with control group. ${ }^{\dagger} p<0.05$.
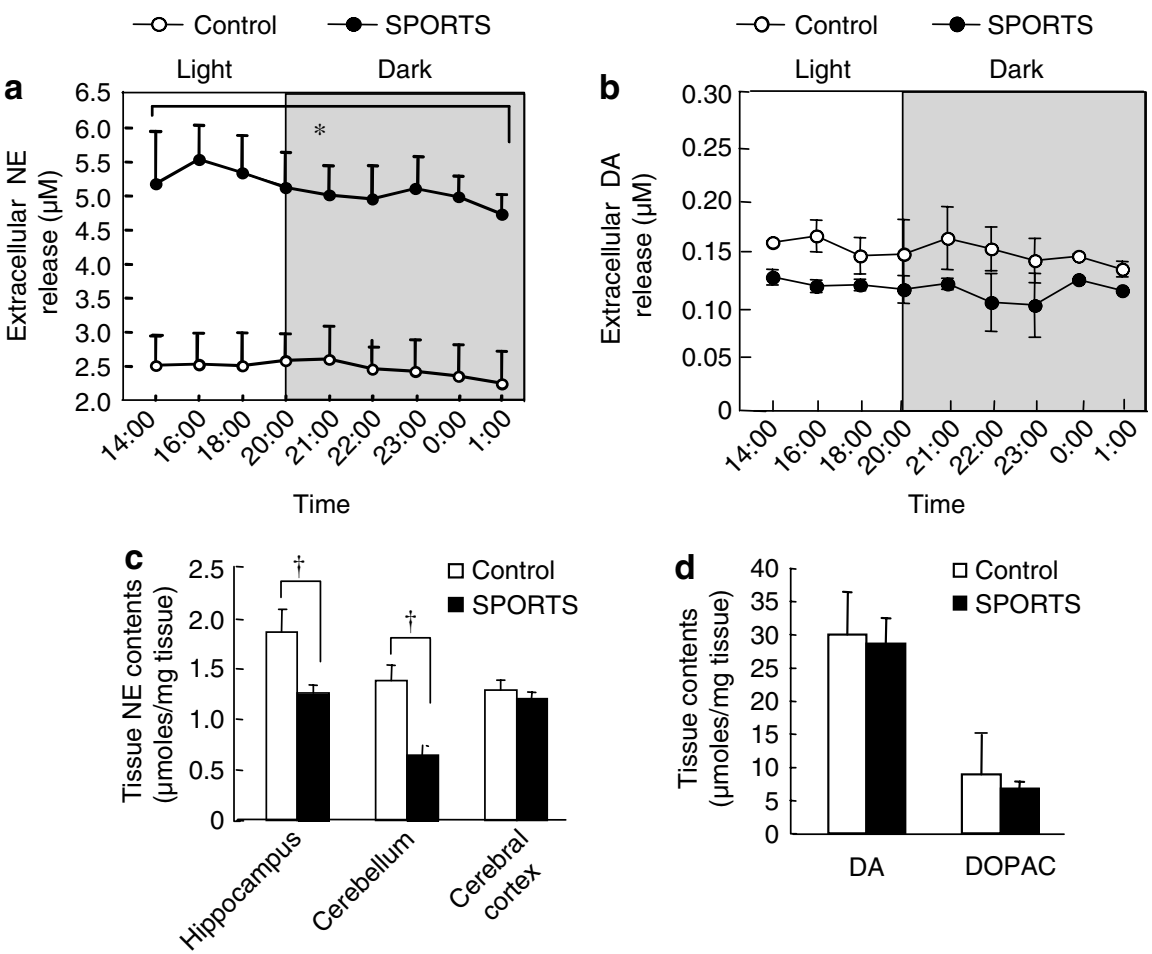

Figure 2 Extracellular norepinephrine (NE) levels were increased in the hippocampus of SPORTS rats. (a) Extracellular NE level in the hippocampus of SPORTS (closed circles) and control (open circles) rats at 16 weeks of age. Perfusate samples were collected at each time point throughout the day to night time in conscious rats. (b) Extracellular dopamine (DA) level in the striatum. (c) NE content in the tissue homogenates of hippocampus, cerebellum, and cerebral cortex from SPORTS and control rats at 16 weeks of age. (d) The concentrations of DA and DA metabolite DOPAC in the striatal homogenate from SPORTS and control rats at 16 weeks of age. Data are means \pm SD for five rats in each group. ${ }^{*} p<0.01,{ }^{\dagger} p<0.05$ compared with control group. 
metabolite DOPAC in the striatum homogenate were the same in the two groups (Figure $2 \mathrm{~d}$ ).

\section{$\alpha_{2}$-ARs were Decreased in the Hippocampus of SPORTS Rats}

The elevated NE was expected to alter the population of NE receptors in the hippocampus of SPORTS rats. To determine the binding abilities of each adrenergic receptor (AR) to NE, we studied $\left[{ }^{3} \mathrm{H}\right] \mathrm{NE}$ binding in the rat hippocampus. Figure $3 \mathrm{a}$ shows the results of $\left[{ }^{3} \mathrm{H}\right] \mathrm{NE}-$ binding assays where the specific binding of $\left[{ }^{3} \mathrm{H}\right] \mathrm{NE}$ to $\alpha_{1^{-}}$, $\alpha_{2^{-}}$, and $\beta$-ARs were examined by the use of the specific competitors prazosin $\left(\alpha_{1 / 2}-\mathrm{AR}\right.$ antagonist), yohimbine $\left(\alpha_{2}\right.$-AR antagonist), propranolol ( $\beta$-AR antagonist), and phenylephrine $\left(\alpha_{1}-\mathrm{AR}\right.$ agonist). As shown in Figure 3a, the intensities of competition for $\left[{ }^{3} \mathrm{H}\right] \mathrm{NE}$ binding to the hippocampal membrane by prazosin and yohimbine were less for SPORTS rats than for control rats. There was no significant difference in the competing abilities for propranolol or phenylephrine between the two groups (Figure 3a). Figure $3 \mathrm{~b}$ and $\mathrm{c}$ shows that the protein levels of $\alpha_{2 \mathrm{~A}}$-AR were decreased in the hippocampus of SPORTS rats at both 4 and 16 weeks of age, and G $\alpha \mathrm{i}$ protein of SPORTS rats at 16 weeks of age was also decreased. The protein expressions of $\alpha_{1}$-AR were, however, not different between SPORTS and control rats.

a

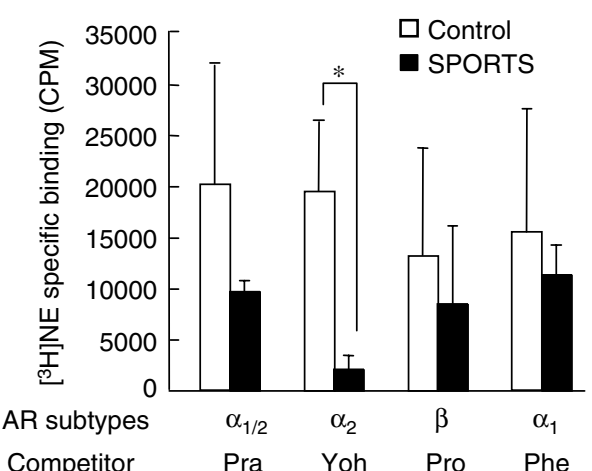

b
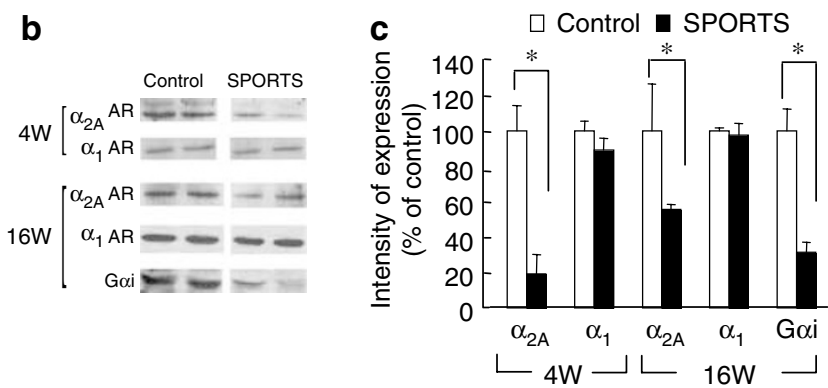

Figure $3 \quad \alpha_{2}$-Adrenergic receptors (ARs) were decreased in the hippocampus of SPORTS rats. (a) $\left[{ }^{3} \mathrm{H}\right]$ norepinephrine (NE) binding to hippocampal $\alpha_{1^{-}}, \alpha_{2^{-}}$, or $\beta$-ARs. Specific binding was measured for SPORTS and control groups at 16 weeks of age with selective agonist or antagonists as competitors for each AR. (b) Western blot analysis of $\alpha_{1}-A R, \alpha_{2 A}-A R$. and $G$ ai protein in the rat hippocampus at 4 or 16 weeks of age. (c) Protein expression levels in SPORTS and control groups determined from the density of blotted bands in (b). Data in (a) and (c) are expressed as means $\pm S D$ for five rats in each group. $* p<0.05$, compared with control group. Pra: prazosin, Yoh; yohimbine, Pro; propranolol, Phe; phenylephrine.

\section{Inhibition of $\alpha_{2}$-AR Suppressed the Running of SPORTS Rats}

To clarify the involvement of hippocampal $\alpha_{2}$-ARs in the hyper-running habituation of SPORTS rats, the selective antagonist (yohimbine) or agonist (clonidine) of $\alpha_{2}$-ARs was administered locally into rat hippocampus and the running activity of each rat was monitored for $2 \mathrm{~h}$. As shown in Figure 4, inhibition of hippocampal $\alpha_{2}$-ARs by yohimbine significantly depressed the running activities of SPORTS but not of control rats. Activation of hippocampal $\alpha_{2}$-ARs with clonidine did not have any effect on running activity of either rat group (Figure 4).

\section{MAOA Activity was Decreased in the Hippocampus of SPORTS Rats}

Increased extracellular NE levels might be due to decreased degradation of NE. Therefore, we measured the MAOA activity in the hippocampus. The hippocampal MAOA activity was significantly decreased in SPORTS rats at 4 weeks of age, but not at 16 weeks of age (Figure $5 a$ ). Then we compared the hippocampal protein expression levels of MAOA, MAOB, and COMT in both rat groups (Figure 5b and c). The MAOA protein level of SPORTS rats was lower than that of control rats at both at 4 and 16 weeks of age. The hippocampal levels of MAOB and COMT were not different between the two groups at 16 weeks of age (Figure $5 b$ and $c$ ). The mRNA level of MAOA in the hippocampus of SPORTS rats was, however, the same as that of control rats both at 4 and 16 weeks of age (Figure $5 \mathrm{~d}$ ). In addition, cDNA cloning showed that SPORTS rats did not have any mutation in the nucleotide sequences for the open reading frame of the MAOA gene (data not shown).

To investigate the rate of breakdown of MAOA in the hippocampus of SPORTS rats, isolated rat hippocampus was incubated with cycloheximide, an inhibitor of protein synthesis, and the degradation rate of the protein was monitored thereafter. Our preliminary experiments did not show any degradation of the MAOA protein in isolated rat hippocampus for up to $60 \mathrm{~min}$ in the incubation medium without cycloheximide (data not shown). As shown in Figure 6, treatment of rat hippocampus with cycloheximide

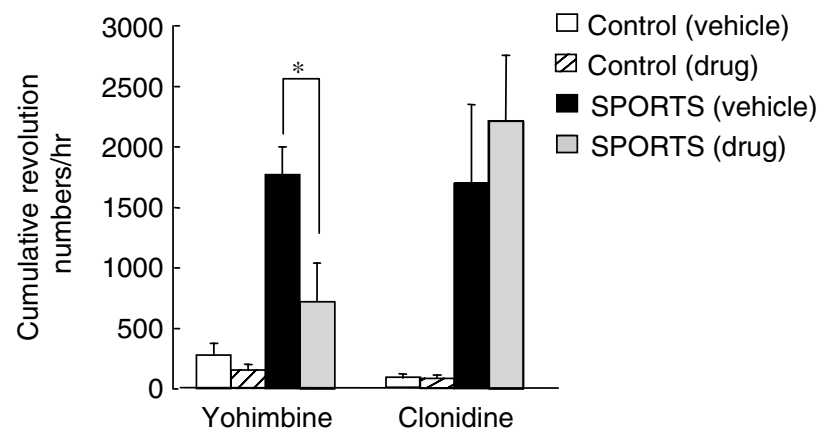

Figure 4 Effect of $\alpha$-adrenergic receptor stimulation or inhibition on the running activity of both SPORTS and control rats. Rat hippocampus was perfused with yohimbine $(20 \mu \mathrm{M})$, clonidine $(100 \mu \mathrm{M})$ or vehicle (Ringer) at a rate of $\mathrm{I} \mu \mathrm{l} / \mathrm{min}$ for $45 \mathrm{~min}$. The revolution number of the running wheel for each rat was recorded for $2 \mathrm{~h}$ after drug treatment, which was finished at $2200 \mathrm{~h}$. Data are expressed as means \pm SD for 3-4 rats. $* p<0.05$. 
a
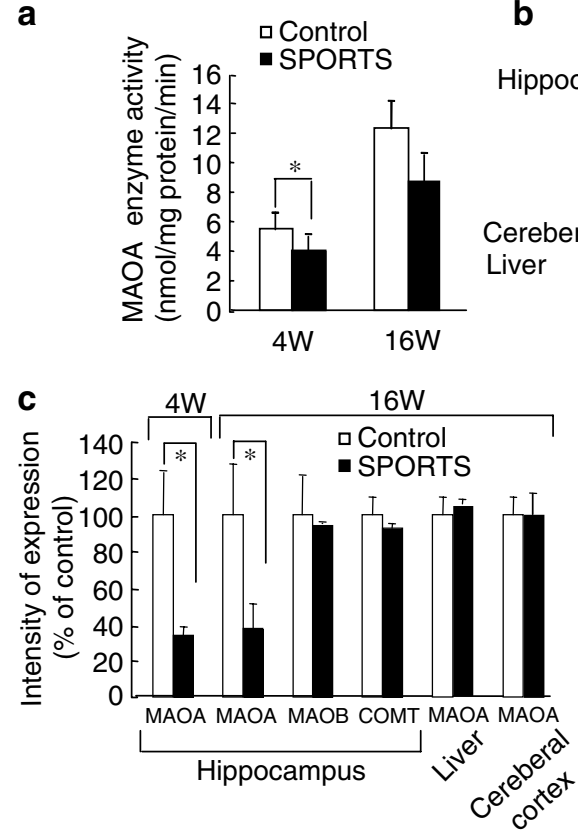

b

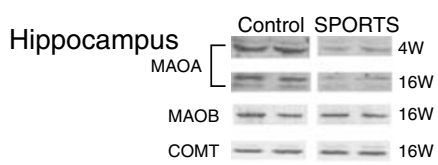

Cereberal cortex MAOA $=-16 \mathrm{~W}$

Liver $\quad$ MAOA $\equiv \equiv 16 \mathrm{~W}$ d

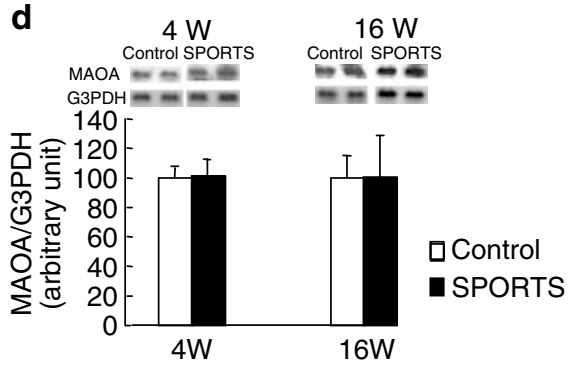

Figure 5 Monoamine oxidase A (MAOA) activity was decreased in the hippocampus of SPORTS rats. (a) MAOA activity in the rat hippocampus at 4 or 16 weeks of age. (b) Western blot analysis of MAOA, MAOB and catechol-O-methyltransferase (COMT). In all, $50 \mu g$ of protein from hippocampus, cerebral cortex, or liver was applied to SDS-PAGE. (c) Protein expression levels in SPORTS and control groups determined from the density of blotted bands in (b). (d) Northern blot analysis of MAOA in the hippocampus. Of total RNA, $25 \mu \mathrm{g}$ was subjected to electrophoresis. The RNA-transferred membrane was hybridized with MAOA probe, washed, and exposed for autoradiography at $-80^{\circ} \mathrm{C}$ for I week. The same membrane was rehybridized with a cDNA probe for rat G3PDH. Data are expressed as means \pm SD for seven (a), four (c), and five (d) rats in each group. *p $<0.05$, compared with control group.

$(1 \mu \mathrm{g} / \mathrm{ml})$ decreased the amount of MAOA protein in the tissue homogenate in a time-dependent manner. Although the initial level (time 0) of MAOA protein was low in the hippocampus of SPORTS rats (Figure 5c), no increase in the degradation rate of MAOA protein was observed in this tissue of SPORTS rats during the $60 \mathrm{~min}$ incubation with cycloheximide (Figure 6a and b).

Intraperitoneal Treatment with Clorgyline, an MAOA Inhibitor, Induces Hyper-Running in Normal Wistar Rats

To investigate whether the low activity of MAOA was responsible for the hyper-running phenotype of SPORTS rats, clorgyline $(1 \mathrm{mg} / \mathrm{kg} \mathrm{BW})$, an inhibitor of MAOA, was administered intraperitoneally to normal Wistar rats. As previously reported (Feldman, 1988), administration of MAOA inhibitor decreased the amount of food intake approximately $50 \%$ in our Wistar rats (data not shown). Therefore, vehicle-treated rats were pair-fed to match clorgyline-induced hypophagia. Chronic treatment with clorgyline decreased the activity of MAOA in the hippocampus but not in the liver of normal Wistar rats (Figure 7a). In contrast, MAOB activity was not changed by the clorgyline treatment (Figure $7 \mathrm{~b}$ ). As shown in Figure $7 \mathrm{c}$, normal Wistar rats with clorgyline treatment increased their wheel-running distance gradually and reached a plateau level that was similar to that of the SPORTS rat (Figure 1a). In contrast, the running activity of vehicle-treated rats was lower than in our preliminary study
(Figure 1a). As shown in Figure 1, the running activity of control rats gradually decreased from 13 weeks of age. Since normal rats at 25 weeks of age were used in the experiments for Figure 7, observed low running activity in the vehicletreated rats might involve the effect of the aging. However, we could not clearly show the relationships between aging and wheel-running activity in the present study. No decrease was observed in the mRNA or protein levels of MAOA, MAOB, and COMT after chronic clorgyline treatment (data not shown).

\section{Local Injection of Clorgyline into Hippocampus Induces Hyper-Running in Normal Wistar Rats}

To clarify the involvement of hippocampal MAOA in the hyper-running habituation of SPORTS rats, clorgyline was administered locally into the hippocampus of normal Wistar rats and the running activity of each rat was monitored for $12 \mathrm{~h}$. As shown in Figure 8, normal Wistar rats with local clorgyline treatment increased their wheelrunning activity.

\section{DISCUSSION}

The SPORTS rat is a good animal model for elucidating the mechanisms responsible for upregulation of running behavior and for investigating the changes in nutrient metabolism induced by high-intensity exercise (MorishimaYamato et al, 2005). This study focused on the increased exercise behavior of SPORTS rats and its relation with the 


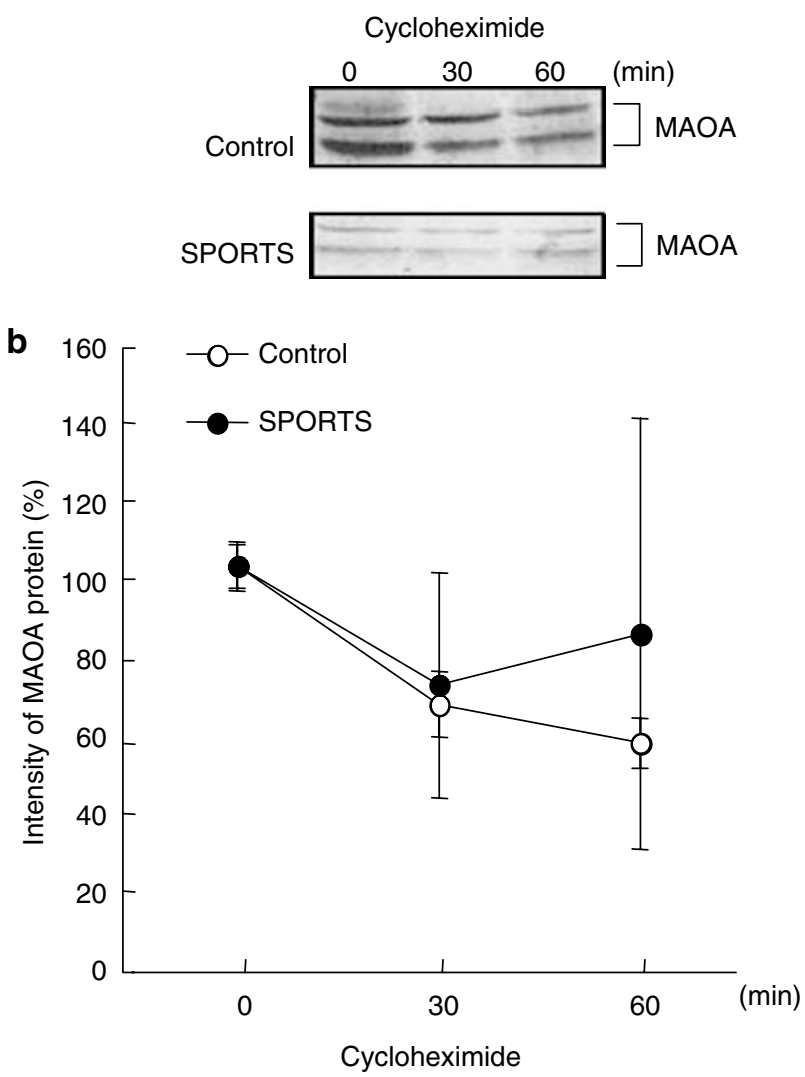

Figure 6 Degradation rate of monoamine oxidase $A(M A O A)$ protein in the isolated rat hippocampus during a 60 min treatment with I $\mu \mathrm{g} / \mathrm{ml}$ cycloheximide. (a) The tissue extracts $(50 \mu \mathrm{g}$ hippocampus $/ 30 \mu \mathrm{l})$ were subjected to SDS-PAGE followed by Western blotting with anti-MAOA antibody. (b) Degradation curves for hippocampal MAOA protein in SPORTS and control groups determined from the density of blotted bands in (a). Initial intensity of MAOA protein (time 0 in (a)) was taken as $100 \%$. Data are expressed as means \pm SD for four rats in each group.

noradrenergic systems in the hippocampus because brain tissue is where a variety of changes in gene expression, hormonal regulation, and neurotransmission have been observed during physical exercise (Tong et al, 2001; Bronikowski et al, 2004; Neeper et al, 1995; Oladehin and Waters, 2001; Bequet et al, 2002; Tumer et al, 2001).

Hippocampal neurotransmission controls memory, learning, stress responses, and behavior in humans and animals (Bremner et al, 1996; Cryan et al, 2004; Dietmar et al, 1998; Galeotti et al, 2004). The NE neurons derived from the locus ceruleus target hippocampus and release NE to modulate brain functions in response to changes in the environment (Bremner et al, 1996). Exercise training is one of the environmental changes that enhance the metabolism and turnover of NE in the hippocampus (Dunn et al, 1996). Although the peripheral infusion of $\mathrm{NE}$ enhances wheel running in rats (Wilckens et al, 1992; Sadalge et al, 2003), whether the NE level in brain modulates running activity was unclear until now. In the present study, even where the rats were housed without the running wheels, the concentration of extracellular NE in the hippocampus of SPORTS rats was two times higher than that of controls at all times. Thus, the elevated NE level in the extracellular fluid of the a

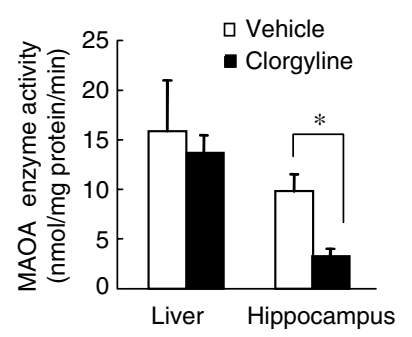

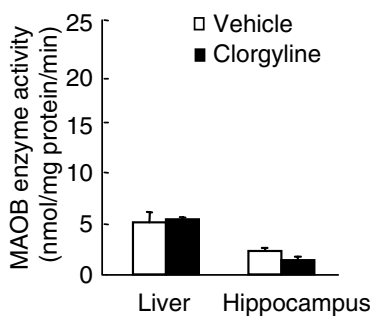

C

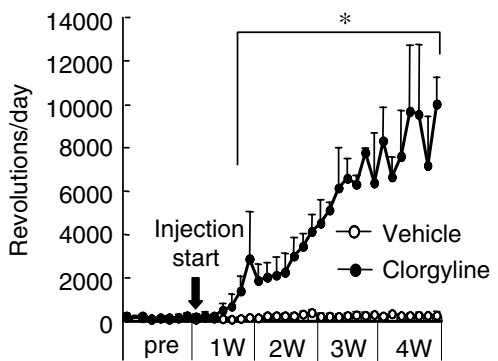

Figure 7 Intraperitoneal treatment with clorgyline, an inhibitor of monoamine oxidase $A$ (MAOA), induces hyper-running in normal Wistar rats. (a) MAOA and (b) MAOB enzyme activity in the hippocampus and liver after chronic treatment of normal Wistar rats with clorgyline $(I \mathrm{mg} / \mathrm{kg}$ $B W$, i.p.). Clorgyline decreases MAOA activity markedly, but not MAOB, activity in the hippocampus of rats. (c) Daily running activity in clorgylinetreated normal Wistar rats. Clorgyline treatment induces hyper-running. Data are expressed as means $\pm S D$ for three rats in each group. ${ }^{*} p<0.05$, compared with vehicle group.

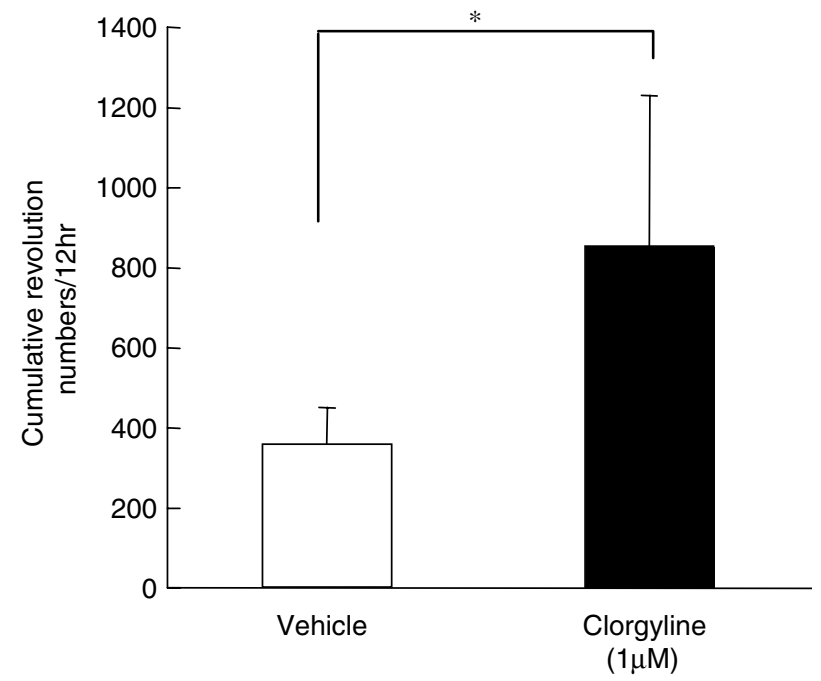

Figure 8 Local administration of clorgyline into hippocampus increases wheel-running activity in normal Wistar rats. Rat hippocampus was perfused with clorgyline $(\mid \mu M)$ or vehicle (Ringer) at a rate of $|\mu| / m i n$ for $60 \mathrm{~min}$. The revolution number of the running wheel for each rat was recorded for $12 \mathrm{~h}$ after drug treatment, which was finished at 2200. Data are expressed as means \pm SD for 5 rats. $* p<0.05$.

hippocampus was related to hyper-running in rodents. The hyperactivity of SPORTS rats in the forced swim test supports this hypothesis. A decrease of immobility time in water is well known to be induced by the treatment of rodents with antidepressant drugs that increase the 
extracellular NE level in the brain. The NE exerts its effects through its receptors (LeDoux, 1994; Cryan et al, 2004; Roberto and Silvio, 2004).

Prolonged NE stimulation causes downregulation of its receptors (Prieto and Giralt, 2002). Thus, elevated extracellular NE was expected to alter the population of ARs in the hippocampus of SPORTS rats. Our finding that radiolabeled $\mathrm{NE}$ binding to hippocampal membrane of SPORTS rats was not strongly affected by prazosin $\left(\alpha_{1 / 2}\right.$-AR antagonist) or yohimbine ( $\alpha_{2}-\mathrm{AR}$ receptor antagonist) suggests that there were reduced densities for the receptors. Prazosin has a minor effect on $\alpha_{1}$-AR-mediated neurotransmission in the hippocampus (Sirvio and Macdonald, 1999), although stimulation of hippocampal $\alpha_{1}$-ARs alters behavioral activity in antidepressant-treated rats (Kostows$\mathrm{ki}, 1985)$. Since the intensity of competition for radiolabeled NE binding to hippocampal membranes by the $\alpha_{1}$-AR agonist phenylephrine was not different between SPORTS and control rats, the reduced receptor density occurred specifically for the $\alpha_{2}$-AR in the hippocampus of SPORTS rats. This conclusion is consistent with our finding that the protein expression level of $\alpha_{2 A}-A R$, but not $\alpha_{1}-A R$, was greatly decreased in the hippocampal homogenate of SPORTS rats. In addition, the decrease in the amount of $\mathrm{G} \alpha \mathrm{i}$ protein supports the evidence for this receptor downregulation (Jewell-Motz et al, 1998; Heck and Bylund, 1998). We conclude that the hippocampal $\alpha_{2}$-ARs were downregulated for SPORTS rats in the resting state without wheel running.

To examine whether the downregulated $\alpha_{2}$-ARs are involved in the increased running behavior of SPORTS rats, the selective $\alpha_{2}$-AR antagonist yohimbine or agonist clonidine was administered into the hippocampus and the running activity of each rat was monitored thereafter. In the present study, local administration of clonidine into the hippocampus did not inhibit the wheel running of SPORTS rats. On the other hand, the hyper-running of SPORTS rats was inhibited markedly by the antagonism of the $\alpha_{2}$-AR with yohimbine. A population of $\alpha_{2}$-ARs is located on presynaptic membranes in brain. These $\alpha_{2}$-ARs bind NE and decrease the release of NE from the presynaptic neurons resulting in a decrease of postsynaptic AR stimulation (Shishikina et al, 2004; Lahdesmaki et al, 2003; Roberto and Silvio, 2004; Heck and Bylund, 1998). Thus, the blockade of presynaptic $\alpha_{2}$-ARs with yohimbine should increase extracellular NE concentration (Galeotti et al, 2004; Prieto and Giralt, 2002). In the present study, the extracellular NE levels were already high in SPORTS rat hippocampus even in the absence of yohimbine (Figure 2a). Thus, observed inhibitory effect of yohimbine on hyperrunning of SPORTS rats might be through antagonism of postsynaptic $\alpha_{2}$-ARs. The precise mechanisms underlying the yohimbine-induced inhibition of hyper-running in SPORTS rats have not been determined in this study. However, our results suggest that the $\alpha_{2}$-ARs are involved in the hyper-running behavior in SPORTS rats.

The molecular mechanisms that raise the extracellular NE level in the hippocampus might be one of the neural bases of the psychological regulation of increased exercise behavior in SPORTS rats. The possibilities that the $\alpha_{2}$-ARs (Roman et al, 2003) or the NE transporters on the presynaptic membranes ( $\mathrm{Xu}$ et al, 2000) are impaired genetically and that this results in an increase in extracellular NE level in the SPORTS rat hippocampus cannot be excluded; however, the decreased NE in the whole homogenate of SPORTS rat hippocampus prompted us to first examine the activity of MAOA, which is the enzyme catalyzing the degradation of monoamines including $\mathrm{NE}$ (Daniel et al, 2001). We found that the enzyme activity of MAOA, but not of MAOB, was decreased in the hippocampus of SPORTS rats. The structural alteration of MAOA protein due to a point mutation in its DNA sequence is known to alter the activity or stability (Jichun et al, 2004; Kevin et al, 2004) of the enzyme. In SPORTS rats, however, the nucleotide sequence for the open reading frame of the MAOA gene was the same as that of control Wistar rats, suggesting that the decreased MAOA activity in the SPORTS rat hippocampus could not be attributed to impaired protein function but could be due to the lowered protein accumulation level. The fact that the level of MAOA mRNA expression was not altered in the hippocampus of SPORTS rats would then indicate that the decrease in the hippocampal MAOA protein in SPORTS rats was independent of transcriptional regulation. Several protein expression levels are regulated by post-transcriptional processes that include breakdown by the proteasome and translational control on the ribosomes (Steinbeck and Methner, 2005; Kevin et al, 2005). Our experiments involving the use of cycloheximide showed that the breakdown of MAOA protein occurred in the hippocampus within $60 \mathrm{~min}$, a time which was shorter than that observed in a previous report where the half-life of MAOA protein in liver was described to be over 2 days (Egashira and Yamanaka, 1981). However, the turnover rate of the protein differs between tissues (Hasegawa et al, 1995). For instance, the half-life of tryptophan hydroxylase in pineal grand was $75 \mathrm{~min}$ as measured in rats with cycloheximide treatment (Sitaram and Lees, 1978), whereas it was 2-3 days in the rat spinal cord (Meek and Neff, 1972). MAOA protein level in liver was not affected in SPORTS or control rats by a short $(90 \mathrm{~min})$ incubation with cycloheximide in our preliminary experiments (data not shown). In the hippocampus with such rapid turnover of MAOA protein, however, the rate of MAOA breakdown for SPORTS rats was almost the same as that for control rats. Thus, the elevated level of extracellular $\mathrm{NE}$ in the hippocampus of SPORTS rats seems to be the result of impaired MAOA protein synthesis that unknown factors contribute to. In this regard, several hormones such as ovarian steroids have been reported to regulate both transcriptional and translational expression of MAOA (Smith et al, 2004). However, little information is available for the precise mechanisms for translation of the MAOA gene, including the transcriptional starting site, the complete sequences of $3^{\prime}$ and $5^{\prime}$ untranslated regions, and the specific binding proteins for MAOA mRNA. Elucidation of these details in future work may allow us to identify candidate genes that generate the SPORTS phenotype.

In the present study, the levels of MAOA and $\alpha_{2}$-ARs were decreased in SPORTS rat hippocampus even before the initiation of the hyper-running ( 4 weeks of age). Therefore some as yet undetermined growth-associated factors might contribute to the determination of the SPORTS phenotype. To test whether the inhibition of MAOA in the brain is sufficient for activating wheel running in the adult rats, the 
MAOA-specific inhibitor clorgyline was administered into normal Wistar rats at 25 weeks of age. The MAOA inhibitors are used clinically for the treatment of psychological disorders including depression (Cases et al, 1995; Finberg et al, 1993). We first examined the effect of intraperitoneal (systemic) clorgyline treatment which has been known to enhance extracellular NE accumulation in several brain regions including hippocampus (Mateo et al, 2001). Clorgyline treatment of our normal Wistar rats increased daily wheel-running activity gradually, and the maximum level was nearly the same as that of the SPORTS strain. To investigate whether the inhibition of hippocampal MAOA itself induces hyper-running behavior, clorgyline was administered locally into the hippocampus of normal Wistar rats and the running activity of rat was monitored thereafter. As shown in Figure 8, local administration of clorgyline increased wheel-running activity, although we could not exclude possibility of involvement of other sites. Given these results, we conclude that the inhibition of hippocampal MAOA is, at least in part, responsible for the hyper-running behavior of SPORTS rats.

Loss of function of MAOA caused by a deficiency in the MAOA gene or decreased activity of the enzyme caused by a MAOA promoter polymorphism is associated with violent, criminal, or impulsive behavior in humans (Brunner et al, 1993). MAOA knockout mice also showed increased aggressive behavior where the brain $\mathrm{NE}$ and serotonin concentrations were markedly increased (Cases et al, 1995; Daniel et al, 2001). Our SPORTS rats, however, did not show any aggressive behavior (data not shown). Therefore, it was unlikely that the systemic decrease of MAOA activity occurs in SPORTS rats. We showed here that the protein expression level of MAOA was not altered at least in the liver and cerebral cortex of SPORTS rats (Figure 5). Whether the MAOA activity was decreased in all brain regions or in other peripheral tissues of SPORTS rats, however, has not been determined in this study. Further studies are needed to clarify the involvement of MAOA in other regions or tissues in generating the phenotype of SPORTS rats.

The antidepressants that target noradrenergic or serotonergic neurons or the deficiency of the NE transporter gene in mice cause increased sensitivities of the $D_{2} / D_{3} D A$ receptors (Xu et al, 2000). Thus, dopaminergic functions might be involved in the control of exercise behavior in SPORTS rats. The DAs in the brain have been implicated in the wheel running of rodents (Rhodes et al, 2003; Leng et al, 2004). Because the hippocampus has only a small population of dopaminergic neurons, we failed to detect measurable DAs in this tissue. However, we did observe a normal expression level of MAOB, the highly selective degradation enzyme for DA, in the hippocampus of SPORTS rats. In general, abnormal levels of striatal DA in humans or animals are associated with changes in emotional and motivational behavior (Rhodes et al, 2003; Leng et al, 2004). We measured DA concentrations in the rat striatum, where a large number of dopaminergic neurons exist (Gallego et al, 2003; Leng et al, 2004). However, there was no significant change in the striatal DA and its metabolite levels in the extracellular fluid or tissue homogenates of SPORTS rats. Therefore, the DA level itself was unlikely to be involved in the hyper-running of SPORTS rats. The sensitivities or functions of DA receptors were not examined in this study.

In summary, we investigated the concentration and the regulation of NE in the hippocampus of SPORTS rats. The results showed that SPORTS rats had an elevated level of extracellular NE in the hippocampus. Impairment of MAOA activity and $\alpha_{2}$-AR downregulation could be involved in initiation of the hyper-running of this model animal. Inhibition of MAOA increased wheel running in normal Wistar rats. Modulation of NE transmission in the brain could be one strategy for enhancing exercise activity in healthy and diseased humans.

\section{ACKNOWLEDGEMENTS}

This study was supported in part by a Grant-in-Aid for Scientific Research from the Ministry of Education, Science, Sports, and Culture and Technology, Japan to Yutaka Nakaya (17500429) and Nagakatsu Harada (16700461).

\section{REFERENCES}

Bequet F, Gomez-Merino D, Berthelot M, Guezennec CY (2002). Evidence that brain glucose availability influences exerciseenhanced extracellular 5-HT level in hippocampus: a microdialysis study in exercising rats. Act Physiol Scand 176: 65-69.

Biddle SJH, Fox KR (1998). Motivation for physical activity and weight management. Int J Obes Relat Metab Disord 22: S39-S47.

Bremner JD, Krystal JH, Southwick SM, Charney DS (1996). Noradrenergic mechanisms in stress and anxiety: I. Preclinical studies. Synapse 23: 28-38.

Bronikowski AM, Rhodes JS, Garland Jr T, Prolla TA, Awad TA, Gammie SC (2004). The evolution of gene expression in mouse hippocampus in response to selective breeding for increased locomotor activity. Evolution 58: 2079-2086.

Brunner HG, Nelen M, Breakefield XO, Ropers HH, Oost BAV (1993). Abnormal behavior associated with a point mutation in the structural gene for monoamine oxidase A. Science 262: 578-580.

Cahill L, Prins B, Weber M, McGaugh JL (1994). Adrenergic activation and memory for emotional events. Nature 371: 702-704.

Carter AJ (1997). Hippocampal noradrenaline release in awake, freely moving rats is regulated by alpha- 2 adrenoceptors but not by adenosine receptors. J Pharmacol Exp Ther 281: 648-654.

Cases O, Seif I, Grimsby J, Gaspar P, Chen K, Pournin S et al (1995). Aggressive behavior and altered amounts of brain serotonin and norepinephrine in mice lacking MAOA. Science 268: $1763-1766$.

Cortez MY, Torgan CE, Brozinick Jr JT, Ivy JL (1991). Insulin resistance of obese Zucker rats exercise trained at two different intensities. Am J Physiol 261: E613-E619.

Cryan JF, O'Leary OF, Jin SH, Friedland JC, Ouyang M, Hirsch BR et al (2004). Norepinephrine-deficient mice lack responses to antidepressant drugs, including selective serotonin reuptake inhibitors. Proc Natl Acad Sci USA 101: 8186-8191.

Daniel PH, Chen K, Shin JC (2001). Biochemical, behavioral, physiologic, and neurodevelopmental changes in mice deficient in monoamine oxidase A or B. Brain Res Bull 56: 453-462.

Dietmar B, Dennis LM, Anne MA, Christine HW, Douglas F, Armin $\mathrm{H}$ et al (1998). Altered brain serotonin homeostasis and locomotor insensitivity to 3, 4-methyledioxymethamphetamine ('Ecstasy') in serotonin transporter-deficient mice. Mol Pharmacol 53: 649-655. 
Dishman RK (1981). Biologic influences on exercise adherence. Res Q Exerc Sport 52: 143-159.

Dunn AL, Reigle TG, Yougstedt SD, Armstrong RB, Dishman RK (1996). Brain norepinephrine and metabolites after treadmill training and wheel running in rats. Med Sci Sports Exerc 28: 204-209.

Egashira T, Yamanaka Y (1981). Further studies on the synthesis of A-form monoamine oxidase. Jpn J Pharmacol 31: 763-770.

Eikelboom R (1999). Human parallel to voluntary wheel running: exercise. Anim Behav 57: F11-F12.

Feldman JM (1988). Effect of the monoamine oxidase inhibitors clorgyline and pargyline on the hyperphagia of obese mice. Behav Brain Res 29: 147-158.

Fiebig RG, Hollander JM, Ney D, Boileau R, Jeffery E, Ji LL (2002). Training down-regulates fatty acid synthase and body fat in obese Zucker rats. Med Sci Spor Exer 34: 1106-1114.

Finberg JPM, Pacak K, Goldstein DS, Kopin IJ (1994). Modification of cereberal cortical norepinephrine release by chronic inhibition of MAOA. J Neural Transm 41: 123-125.

Finberg JPM, Pacak K, Kopin JJ, Goldstein DS (1993). Chronic inhibition of monoamine oxidase type A increases noradrenaline release in rat frontal cortex. Naunyn-Schmiedeberg's Arch Pharmacol 347: 500-505.

Galeotti N, Bartolini A, Ghelardini C (2004). Alpha-2 agonistinduced memory impairment is mediated by the alpha-2Aadrenergic receptor subtype. Behav Brain Res 153: 409-417.

Gallego M, Setien R, Izquierdo MJ, Casis O, Casis E (2003). Diabetes-induced biochemical changes in central and peripheral catecholaminergic systems. Physiol Res 52: 735-741.

Harada N, Takishita E, Ishimura N, Minami A, Sakamoto S, Nakaya Y (2002). Combined effect of ACE inhibitor and exercise training on insulin resistance in type 2 diabetic rats. Life Sci 70: $1811-1820$.

Hasegawa H, Kojima M, Oguro K, Nakanishi N (1995). Rapid turnover of tryptophan hydroxylase in serotonin producing cells: demonstration of ATP-dependent proteolytic degradation. FEBS Lett 368: 151-154.

Heck DA, Bylund DB (1998). Differential down-regulation of alpha-2 adrenergic receptor subtypes. Life Sci 62: 1467-1472.

Jewell-Motz EA, Donnelly ET, Eason MG, Liggett SB (1998). Agonist-mediated downregulation of $\mathrm{G} \alpha \mathrm{i}$ via the $\alpha 2$-adrenergic receptor is targeted by receptor-Gi interaction and is independent of receptor signaling and regulation. Biochemistry 37: 15720-15725.

Jichun M, Yoshimura M, Yamashita E, Nakagawa A, Ito A, Tsukihara T (2004). Structure of rat monoamine oxidase A and its specific recognitions for substrates and inhibitors. J Mol Biol 338: 103-114.

Kevin C, Daniel PH, Weihua W, Igor R, Shin JC (2004). A spontaneous point mutation produces monoamine oxidase $\mathrm{A} / \mathrm{B}$ knock-out mice with greatly elevated monoamines and anxietylike behavior. J Biol Chem 279: 39645-39652.

Kevin C, Xiao-Ming O, Gao C, Si HC, Shin JC (2005). R1, a novel repressor of the human monoamine oxidase A. J Biol Chem 280: $11552-11559$.

Kostowski W (1985). Possible relationship of the locus coeruleushippocampal noradrenergic neurons to depression and mode of action of antidepressant drugs. Pol J Pharnac 37: 727-743.

Lackovic Z, Salkovic M, Kuci Z, Relja M (1990). Effect of longlasting diabetes mellitus on rat and human brain monoamines. $J$ Neurochem 54: 143-147.

Lahdesmaki J, Sallinen J, MacDonald E, Sirvio J, Scheinin M (2003). Alpha2-adrenergic drug effects on brain monoamines, locomotion, and body temparature are largely abolished in mice lacking the alpha 2A-adrenoceptor subtype. Neuropharmacology 44: 882-892.

Lapier TLK, Swislocki ALM, Clark RJ, Rodnick KJ (2001). Voluntary running improves glucose tolerance and insulin resistance in female spontaneously hypertensive rats. Am J Hypertens 14: 708-715.

LeDoux JE (1994). Emotion, memory and the brain. Sci Am 270: 50-57.

Leng A, Mura A, Hengerer B, Feldon J, Ferger B (2004). Effects of blocking the dopamine depletion with 1-methyl-4-phenyl-1, 2, 3, 6-tetrahydropyridine (MPTP) on voluntary wheel running in mice. Behav Brain Res 154: 375-383.

Marshall JF, Friedman MI, Heffner TG (1976). Reduced anorexic and locomotor-stimulant action of D-amphetamine in alloxandiabetic rats. Brain Res 111: 428-432.

Mateo Y, Fernandez-Pastor B, Meana JJ (2001). Acute and chronic effects of desipramine and clorgyline on alpha2-adrenoceptors regulating noradrenergic transmission in the rat brain: a dualprobe microdialysis study. Br J Pharmacol 133: 1362-1370.

Meek JL, Neff NH (1972). Tryptophan 5-hydroxylase: approximation of half-life and rate of axonal transport. J Neurochem 19: 1519-1525.

Mingjie Z, Nataliya PV (1997). A one-step fluorometric method for the continuous measurement of monoamine oxidase activity. Anal Biochem 253: 169-174.

Morishima-Yamato M, Hisaoka F, Shinomiya S, Harada N, Matoba $\mathrm{H}$, Takahashi A et al (2005). Cloning and establishment of a line of rats for high levels of voluntary wheel running. Life Sci 77: 551-561.

Neeper SA, Goomez-Pinilla F, Choi J, Cotman C (1995). Exercise and brain neurotrophins. Nature 373: 109.

Oladehin A, Waters RS (2001). Location and distribution of Fos protein expression in rat hippocampus following acute moderate aerobic exercise. Exp Brain Res 137: 26-35.

Paxinos G, Watson C (1986). The Rat Brain in Stereotaxic Coordinates, 2nd edn. Academic Press: Sydney.

Phillips EM, Schneider JC, Mercer GR (2004). Motivating elders to initiate and maintain exercise. Arch Phys Med Rehabil 85: S52-S57.

Prieto M, Giralt TM (2002). Desensitization of alpha2-adrenoceptors which regulate noradrenaline synthesis and release after chronic treatment with clorgyline in the rat brain. Pharmacology 65: $49-56$

Rhodes JS, Garland Jr T, Gammie SC (2003). Patterns of brain activity associated with variation in voluntary wheel running behavior. Behav Neurosci 117: 1243-1256.

Roberto WI, Silvio G (2004). Role of presynaptic alpha2adrenoceptors in antidepressant action: recent findings from microdialysis studies. Prog Neuro-psychopharmacol Biol Psychol 28: 819-827.

Roman T, Schmitz M, Polanczyk GV, Eizirik M, Rohde LA, Hutz $\mathrm{MH}$ (2003). Is the alpha-2A adrenergic receptor gene (ADRA2A) associated with attention-deficit/hyperactivity disorder? $\mathrm{Am} \mathrm{J}$ Med Genet 120: 116-120.

Sadalge A, Coughlin L, Fu H, Wang B, Valladares O, Valentino R et al (2003). Alpha $1 \mathrm{~d}$ adrenoceptor signaling is required for stimulus induced locomotor activity. Mol Psychol 8: 664-672.

Sei H, Sano A, Oishi K, Fujihara H, Kobayashi H, Ishida $\mathrm{N}$ et al (2003). Increase of hippocampal acetylcholine release at the onset of dark phase is suppressed in a mutant mice model of evening-type individuals. Neuroscience 117: 785-789.

Sheard NF (2003). Moderate changes in weight and physical activity can prevent or delay the development of type 2 diabetes mellitus in susceptible individuals. Nutr Rev 61: $76-79$.

Sherwin CM (1998). Voluntary wheel running: a review and novel interpretation. Anim Behav 56: 11-27.

Shishikina GT, Kalinina TS, Dygalo NN (2004). Attenuation of alpha 2A-adrenergic receptor expression in neonatal rat brain by RNA interference or antisense oligonucleotide reduced anxiety in adulthood. Neuroscience 129: 521-528. 
Sirvio J, Macdonald E (1999). Centaral alpha-adrenoceptors: their role in the modulation of attention and memory formation. Pharmacol Ther 83: 49-65.

Sitaram BR, Lees GJ (1978). Diurnal rhythm and turnover of tryptophan hydroxylase in the pineal gland of the rat. $J$ Neurochem 31: 1021-1026.

Smith LJ, Henderson JA, Abell CW, Bethea CL (2004). Effects of ovarian steroids and raloxifene on proteins that synthesize, transport, and degrade serotonin in the rephe region of macaques. Neuropsychopharmacology 29: 2035-2045.

Steinbeck JA, Methner A (2005). Translational downregulation of the noncatalytic grouwth factor receptor TrkB. T1 by ischemic preconditioning of primary neurons. Gene Expression 12: 99-106.

Swallow JG, Carter PA, Garland Jr T (1998). Artificial selection for increased wheel-running behavior in house mice. Behav Genet 28: 227-237.

Tong L, Shen H, Perreau VM, Balazs R, Cotman CW (2001). Effects of exercise on gene-expression profile in the rat hippocampus. Neurobiol Dis 8: 1046-1056.
Tumer N, Demirel HA, Serova L, Sabban EL, Broxson CS, Powers SK (2001). Gene expression of catecholamine biosynthetic enzymes following exercise: modulation by age. Neuroscience 103: 703-711.

Weinsier RL, Hunter GR, Heini AF, Goran MI, Sell SM (1998). The etiology of obesity: relative contribution of metabolic factors, diet, and physical activity. Am J Med 105: 145-150.

Wilckens T, Schweiger U, Pirke KM (1992). Activation of $\alpha 2$ adrenoceptors suppresses excessive wheel running in the semistarvation-induced hyperactive rat. Pharmacol Biochemi Behav 43: 733-738.

$\mathrm{Xu}$ F, Gainetdinov RR, Wetsel WC, Jones SR, Bohn LM, Miller GW et al (2000). Mice lacking the norepinaphrine transporter are supersensitive to psychostimulants. Nat Neurosci 3: $465-471$.

Yamato T, Misumi Y, Yamasaki S, Kino M, Aomine M (2004). Diabetes mellitus decreases hippocampal release of neurotransmitters: an in vivo microdialysis study of awake, freely moving rats. Diabet Nutr Metab 17: 128-136. 